\title{
Optical and structural studies of vanadium pentoxide thin films
}

\author{
S. Ganeshan ${ }^{1}$, P. Ramasundari ${ }^{2}$, A. Elangovan ${ }^{3}$ and R. Vijayalakshmi ${ }^{4}$ \\ ${ }^{1}$ Department of Physics, Vivekananda College, Madurai \\ ${ }^{2}$ P. G. \& Research Department of Physics, S. V. N. College, Madurai \\ ${ }^{3}$ P. G. \& Research Department of Chemistry, Thiagarajar College, Madurai \\ ${ }^{4}$ P. G. \& Research Department of Physics, Thiagarajar College, Madurai \\ sganeshanmdu@gmail.com, ramyarv@rediffmail.com
}

Recently, transition metal oxides like Vanadium pentoxide have become a subject of intensive studies. The particular physical and chemical properties of these materials allow a wide range of practical applications such as electrochromic devices, cathode electrodes for lithium batteries, humidity sensors. The $\mathrm{V}_{2} \mathrm{O}_{5}$ film was prepared by an electrodeposition technique. The structural and optical properties were studied by XRay Diffraction (XRD), scanning electron microscopy (SEM), UV-Visible and Fourier Transform Infrared Spectroscopy (FT-IR). XRD spectra recorded has been observed and compared with the JCPDS values. SEM images showed very smooth surface morphology and the elemental compositions of the film were confirmed by EDAX. The transmittance of the $\mathrm{V}_{2} \mathrm{O}_{5}$ films showed $75 \%$ at $425 \mathrm{~nm}$ for the as-deposited substrate. The energy band gap of the films was found to be $2.45 \mathrm{eV}$ and the band assignments of the $\mathrm{V}_{2} \mathrm{O}_{5}$ film are comparable with the reported values.

Keywords: Electrodeposition, optical properties, X-ray diffraction.

Received: 5 February 2016

Revised: 11 May 2016

\section{Introduction}

$\mathrm{V}_{2} \mathrm{O}_{5}$ is an important material among other transition metal oxides from the view point of its novel electronic and optical characteristics in thin film form, leading to applications in lithium solid state micro batteries, gas sensors and electrochromic display devices $[1,2]$.The vanadium-oxygen system has been intensively studied by theoretical and experimental techniques. Vanadium oxide is used in thermal sensing and switching. Vanadium pentoxide films have been prepared using various physical and chemical techniques, such as thermal evaporation, electron beam evaporation, sol-gel, electrochemical deposition and pulsed laser ablation [3-6]. Some unique features of $\mathrm{V}_{2} \mathrm{O}_{5}$ include its orthorhombic layered structure, high electrochromic activity, high stability and ease of thin film formation by numerous deposition techniques. Among the various preparation methods, the electrodeposition method was one of the simplest methods, due to its deposition rate, good uniformity on the substrates and thickness control of the film. The main advantage of this electrodeposition coating is the conformal resist layer, independent of the substrate geometry. Electrodeposition coating is the most suited technique to pattern structures that run in and across cavities or when a smaller line width is required. In this present work, the films were prepared by an electrodeposition technique and were characterized to study the optical and structural properties using XRD, SEM with EDAX, UV-Vis Spectroscopy and FT-IR Spectra.

\section{Experimental}

In electrodeposition techniques, structurally and compositionally-modulated alloys and compounds can be deposited and the deposition can be carried out at room temperature enabling the formation of the semiconductor junctions without interdiffusion. The $\mathrm{V}_{2} \mathrm{O}_{5}$ films were prepared by electrodeposition technique having a bath $0.2 \mathrm{M}$ of vanadium pentoxide powder mixed with hydrogen peroxide which was used as the stock solution. The parameters like the concentration of the solution, $\mathrm{pH}$, current and temperature were optimized. The electrodeposition process was carried out with three electrode systems, one is ITO coated plate acting as working electrode, the other the platinum electrode as counter electrode and the third one was the saturated calomel electrode (SCE) as the reference electrode. Two grams of vanadium pentoxide of $99 \%$ purity and $30 \%$ of sulfuric acid were added to avoid the effervescence produced in the solution. Then the stock solution was diluted to get the concentration of $0.1 \mathrm{M}$. The $\mathrm{pH}$ of the solution was maintained as 3.0 and the deposition current was fixed as $1 \mathrm{~mA}$ and the temperature maintained at the room temperature. The crystallographic structure of the film was determined from Powder X-ray diffraction patterns obtained by using BRUKER ECO D8 Advance diffractometer with a monochromatic 
CuK $\alpha$ radiation $(\lambda=0.15406 \mathrm{~nm}, 40 \mathrm{kV}, 20 \mathrm{~mA})$. The surface morphology was studied using SEM (BRUKER ECO D8 ZEISS). The Compositional analysis was done using EDAX spectrometer attached to SEM. The optical transmission studies were done using UV-Vis Spectrophotometer (HP2000). FTIR Spectra were obtained from Perkin-Elmer make model spectrum RXI spectrophotometer.

\section{Results and discussion}

\subsection{XRD Analysis}

Figure 1 shows the diffraction pattern of $\mathrm{V}_{2} \mathrm{O}_{5}$ thin film which was deposited on the ITO substrate. From the analysis, it was found that the $\mathrm{V}_{2} \mathrm{O}_{5}$ film exhibited uniform thickness [7,8]. The XRD analysis proves that the $\mathrm{V}_{2} \mathrm{O}_{5}$ films exhibit polycrystalline nature and the diffraction peaks for $\left(\begin{array}{llll}2 & 2 & 0\end{array}\right)$, ( $\left.\begin{array}{lll}3 & 2 & 0\end{array}\right)$ and $\left(\begin{array}{lll}3 & 0 & 1\end{array}\right)$ planes were prominent. The other low intensity peaks showed that the as-deposited film has coarsely fine crystallites and nanocrystallites. Sharp diffraction peaks at positions $2 \theta=22.4^{\circ}, 27.14^{\circ}$ and $52.22^{\circ}$ correspond to the (2 20 ), ( $\left.\begin{array}{lll}3 & 2 & 0\end{array}\right)$ and $\left(\begin{array}{lll}3 & 0 & 1\end{array}\right)$ planes respectively. The XRD pattern suggests that the film is polycrystalline with varying degree of orientation and has FCC structure when compared with the JCPDS (03-0206) value. The smoothness of the XRD pattern confirms the uniformity in the grown film. The average particle size, which was calculated using the Scherrer relation, ranges from $28.21 \mathrm{~nm}$ to $30.81 \mathrm{~nm}$.

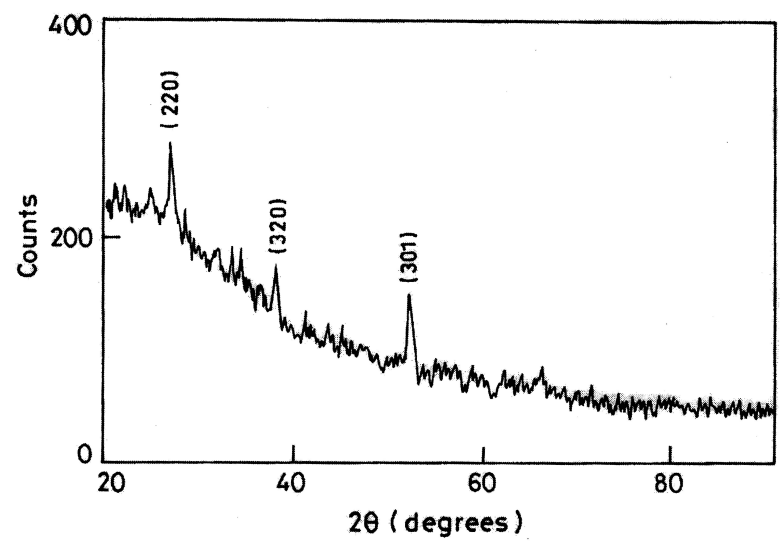

FIG. 1. XRD pattern images of $\mathrm{V}_{2} \mathrm{O}_{5}$ film on ITO substrate

\subsection{Surface morphology studies: SEM with EDAX}

The microstructure and morphology analysis of the as-deposited $\mathrm{V}_{2} \mathrm{O}_{5}$ thin film was carried out. The SEM image in Fig. 2 shows that the film is nearly homogeneous without any pinholes or cracks and covers the substrate well. The particles are spherical in shape. The particle size observed from the SEM images was of the order of $100-200 \mathrm{~nm}$ [9]. Fig. 3 shows the elemental composition of the as deposited $\mathrm{V}_{2} \mathrm{O}_{5}$ film. The presence of vanadium and oxygen were confirmed by EDAX analysis and their atomic weight percentages are calculated as $10.45 \%$ and $28.33 \%$ for vanadium and oxygen respectively.
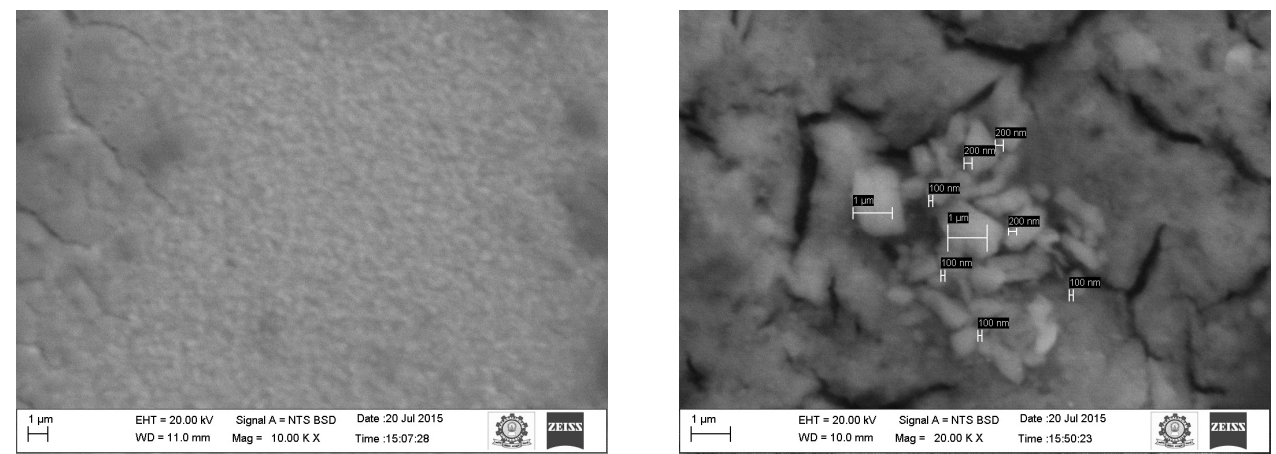

FIG. 2. SEM images of as deposited $\mathrm{V}_{2} \mathrm{O}_{5}$ film on ITO substrate 

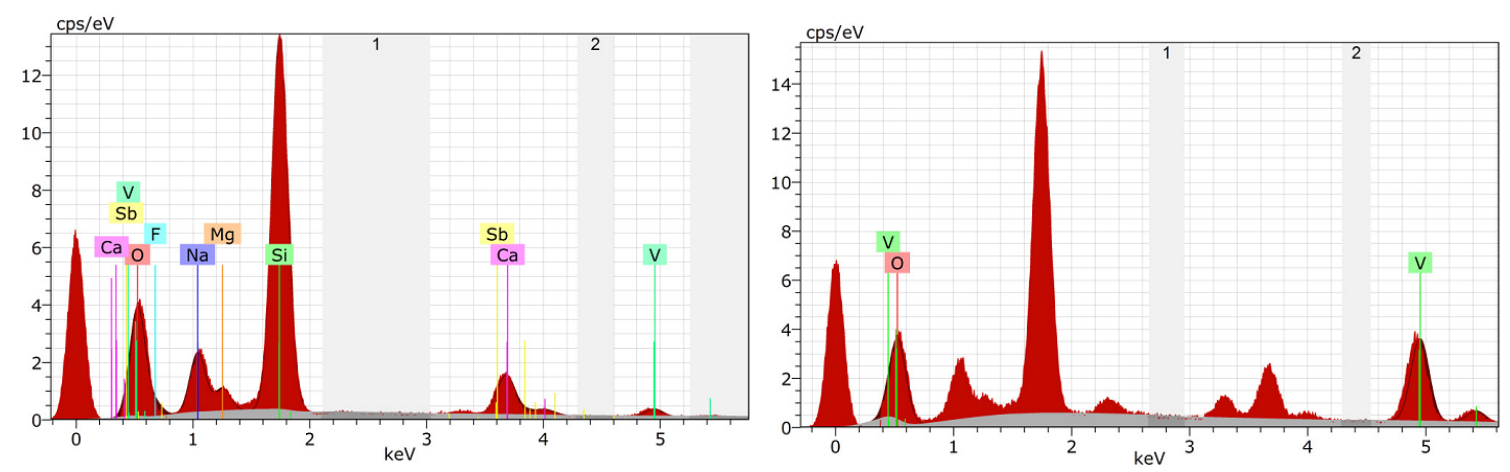

FIG. 3. EDAX spectra of as deposited $\mathrm{V}_{2} \mathrm{O}_{5}$ film on ITO substrate

\subsection{FTIR}

The FTIR spectrum of $\mathrm{V}_{2} \mathrm{O}_{5}$ film is portrayed in Fig. 4. FTIR investigation was performed to study the structural changes and band stretching of vanadium pentoxide. The band at $841 \mathrm{~cm}^{-1}$ corresponds to the polycrystalline $\mathrm{V}_{2} \mathrm{O}_{5}$ also the band at $814 \mathrm{~cm}^{-1}$ is assigned to the crystalline $\mathrm{V}_{2} \mathrm{O}_{5}$. A shoulder type of vanadium band is observed at $767 \mathrm{~cm}^{-1}$ and bands located at $530 \mathrm{~cm}^{-1}, 521 \mathrm{~cm}^{-1}$ are assigned to the stretching mode of the oxygen which is shared between 3 vanadium atoms. The band at $431 \mathrm{~cm}^{-1}$ is assigned to the bending vibrations of the bound oxygen which is shared by 2 vanadium atoms $[10,11]$.

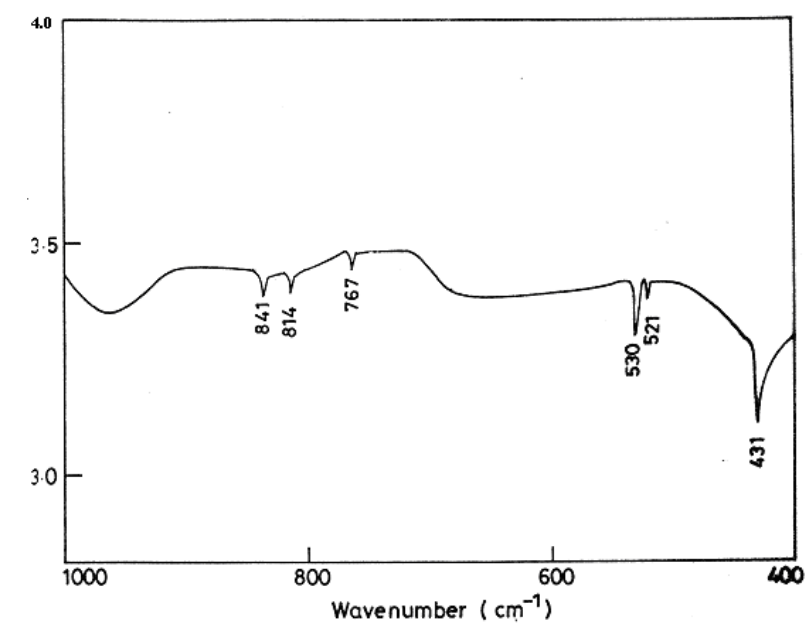

FIG. 4. FTIR Spectra of the $\mathrm{V}_{2} \mathrm{O}_{5}$ film

\subsection{Optical studies}

The UV-VIS spectrum measured for $\mathrm{V}_{2} \mathrm{O}_{5}$ film is shown in Fig. 5(b) and the band gap calculated from Fig. 5(a). The optical parameters are calculated from the transmittance spectrum in the $300 \mathrm{~nm}$ to $800 \mathrm{~nm}$ wavelength region. The as-deposited film has a steady transmittance of $75 \%$ in the visible region. The oscillations in the curves were due to interference effects that depend on the film thickness and the refractive index. The plot is linear, indicating a direct optical transition and the evaluated energy gap is $2.45 \mathrm{eV}$, which agrees with the reported values [12,13] and is similar to the value reported in the pulsed laser deposition technique [13]. Given this data, one can say that a high quality $\mathrm{V}_{2} \mathrm{O}_{5}$ thin film was obtained using the electrodeposition method.

\section{Conclusion}

Polycrystalline $\mathrm{V}_{2} \mathrm{O}_{5}$ thin films were deposited on ITO substrate by electrodeposition method and the films were well adherent, uniform and pinhole-free. The XRD pattern of the $\mathrm{V}_{2} \mathrm{O}_{5}$ film showed a polycrystalline nature with a preferential $\left(\begin{array}{lll}3 & 0 & 1\end{array}\right)$ orientation. Morphological studies showed a well-defined structure and elemental composition. The optical band gap of the $\mathrm{V}_{2} \mathrm{O}_{5}$ thin film was found to be $2.45 \mathrm{eV}$. The electrochromic studies and coloration efficiency of the vanadium pentoxide thin films are areas for future exploration. 

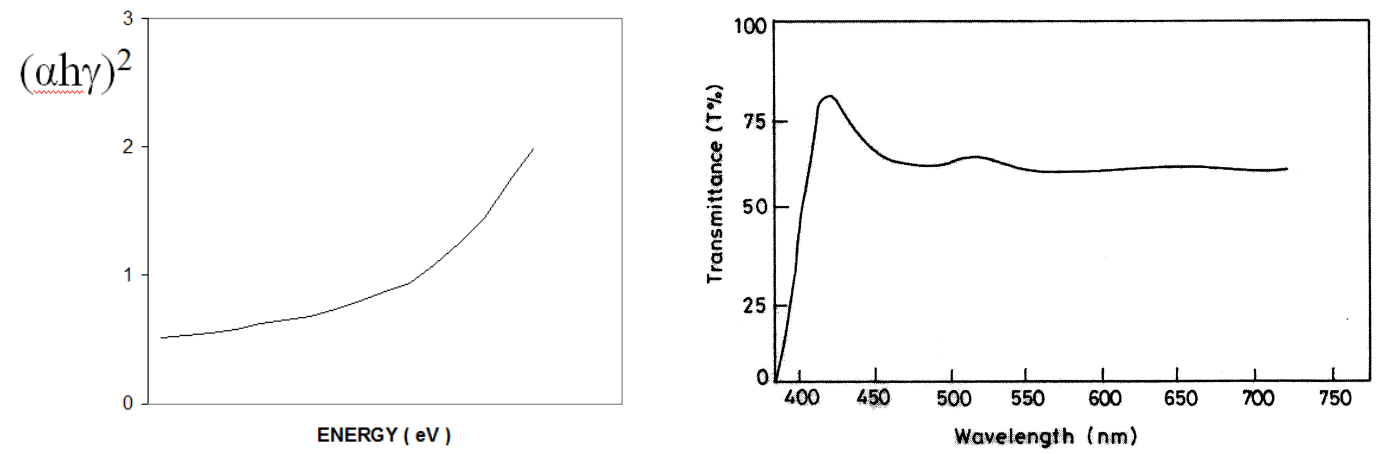

FIG. 5. (a) $(\alpha h \gamma)^{2}$ versus Photon energy film for $\mathrm{V}_{2} \mathrm{O}_{5}$ thin film; (b) Transmittance curve for $\mathrm{V}_{2} \mathrm{O}_{5}$ thin film

\section{References}

[1] Julien C. Electrochemical properties of disordered cathode materials. Ionics, 1996, 2 (3-4), P. 169-178 .

[2] Ramana C.V., Hussain O.M., Srinivasulu Naidu B., Reddy P. Influence of substrate temperature on the composition and structural properties of electron beam evaporated $\mathrm{V}_{2} \mathrm{O}_{5}$ thin films. J. Vaccum, 1997, 48 (5), P. 431-434.

[3] Bates J.B., Dudney N.J., et al. Fabrication and characterization of amorphous lithium electrolyte thin films and rechargeable thin-film batteries. J. Power Sources, 1993, 43, P. 103-110.

[4] Moshfegh A.Z., Ignatiev A. Formation and characterization of thin film vanadium oxides: Auger electron spectroscopy, X-ray photoelectron spectroscopy, X-ray diffraction, scanning electron microscopy, and optical reflectance studies. Thin Solid films, 1991 , 198 (1), P. $251-268$.

[5] Bouzidi A., Benramdane N., et al. Physical Properties of $\mathrm{V}_{2} \mathrm{O}_{5}$ sprayed films. Mater. Sci. Eng. B, 2002,95, P. $141-147$.

[6] Julien C., Haro-Poniatowski E., et al. Growth of $\mathrm{V}_{2} \mathrm{O}_{5}$ thin films by pulsed laser deposition and their applications in lithium microbatteries. Mater. Sci. Eng. B, 1999, 65 (3), P. 170-176.

[7] Ramana C.V., Smith R.J., et al. Correlation between Growth Conditions, Microstructure, and Optical Properties in Pulsed-Laser-Deposited $\mathrm{V}_{2} \mathrm{O}_{5}$ Thin Films. Chem. Matter, 2005, 17 (5), P. 1213-1219.

[8] Shiho lwanaga, Darling R.B., Cooden D.H. Stable and erasable patterning of vanadium pentoxide thin films by atomic force microscope nanolithography. Appl. Physics, 2005, 86, P. 133113.

[9] Olivetti E.A., Kim J.H., et al. Sol-Gel syntheis of Vanadium oxide within a block copolymer matrix. Chem. Matt., 2006,18 , P. $2828-2833$.

[10] Culea E., Nicula A.L., Bratu I. An infrared study of $x \mathrm{~V}_{2} \mathrm{O}_{5} \cdot(1 ? x) \mathrm{B}_{2} \mathrm{O}_{3}$ glasses. Phys. Status. Solid, 1984,83 (1), K15-K18.

[11] Abello L., Husson E., Repelin Y., Lucazeau G. Vibrational spectra and valence force field of crystalline $\mathrm{V}_{2} \mathrm{O}_{5}$. Spectrochimica Acta Part A: Molecular Spectroscopy, 1983, 39 (7), P. 641-651.

[12] Madhuri K.V.,Srinivasa rao K., et al. Optical and electrical properties of $\left(\mathrm{V}_{2} \mathrm{O}_{5}\right)_{1-x}-\left(\mathrm{MoO}_{3}\right)_{x}$ thin films. J. Indian Inst. Sci., 2001, 81, P. 653-658.

[13] Ramana C.V., Naidu B.S., Hussain O.M., Pinto R. Low temperature growth of Vanadium pentoxide thin films produced by Pulsed Laser ablation. J. Phys. D: Appl. Phys., 2001, 34, L35-L38. 